\section{New Test for Thyrotoxicosis?}

In most patients with thyrotoxicosis the diagnosis can be made on clinical grounds alone. ${ }^{1}$ In almost all the remaining patients in whom the diagnosis is more difficult the results of radioiodine $\left({ }^{131} \mathrm{I}\right)$ studies and determinations of proteinbound stable iodine (P.B. $\left.{ }^{127} \mathrm{I}\right)$ in the serum are adequate guides to the diagnosis.

These considerations are rather less true, however, when thyrotoxicosis is suspected during pregnancy. In normal pregnancy complaints of tiredness, palpitation, dyspnoea, and intolerance to heat are not uncommon, and when these symptoms are associated with hot, moist hands, tachycardia, and goitre-all of which may be found in euthyroid pregnant women ${ }^{2-4}$-the doctor will frequently seek help from the laboratory. Unfortunately conventional laboratory studies are of little value in the assessment of thyroid function during pregnancy. The serum-P.B. ${ }^{127} \mathrm{I}$ value, widely accepted as the best test of thyroid function, is normally raised in pregnancy into the non-pregnant thyrotoxic range ${ }^{56}$; high values for basal oxygen consumption are also found ${ }^{78}$; and the use of ${ }^{131} \mathrm{I}$ is contraindicated in view of the risk of radiation damage to the foetus. While the short-lived isotope ${ }^{132}$ I gives less radiation to the foetus, ${ }^{9}$ its routine use in pregnancy cannot be justified, and, indeed, as E. E. Pochin has shown, ${ }^{10}$ the uptake of radioiodine by the thyroid is raised during pregnancy.

Another situation in which it may be difficult to interpret the results of radioiodine studies and P.B. ${ }^{127} \mathrm{I}$ estimations is when the patient has been given iodides, usually in the form of contrast media in radiology. Hence any new laboratory test for thyrotoxicosis is of interest. R. S. Rivlin and his colleagues $^{11}{ }^{12}$ have studied the fasting plasma levels of tyrosine in a group of euthyroid control subjects, a group of thyrotoxic patients, a group of patients suffering from hypothyroidism, and a number of patients with miscellaneous conditions known to give misleading results to conventional tests of thyroid function. They then studied the levels of tyrosine in the blood at 30 minutes, one and a half, three, and in some instances four and a half and six hours after the administration of L-tyrosine powder in a dose of $50 \mathrm{mg}$. per kg. body weight. Thyrotoxic patients had a significantly higher fasting concentration of tyrosine in the plasma than did the euthyroid control group, and the rise observed in the plasma concentration remained consistently higher in thyrotoxic subjects throughout the period of the test, the halfhour value for plasma tyrosine giving best separation between the two groups of patients. Patients with hypothyroidism, on the other hand, had low fasting levels of tyrosine in the plasma and poor responses to the administration of this

\footnotetext{
${ }^{1}$ Crooks, J., Murray, I. P. C., and Wayne, E. J., Quart. F. Med., N.S., 1959, 28, 211.

2 Burt, C. C., Lancet, 1949, $2,787$.

${ }^{9}$ Hare, D. C., and Karn, N. N., Quart. F. Med., O.S., 1929, 22, 381.

- Crooks, J., Aboul-Khair, S. A., Turnbull, A. C., and Hytten, F. E., Lancet, 1964, 2, 334.

- Man, E. B., Heinemann, M., Johnson, C. E., Leary, D. C., and Peters, J. P., F. clin. Invest., 1951, 30, 137.

- Mitchell, M. L., F. clin. Endocr., 1958, 18, 1437.

'Davis, C. H., F. Amer. med. Ass., 1926, 87, 1004

${ }^{8}$ Watrous, J., and Blakely, S. B., Amer. F. Obstet. Gynec., 1952, 64, 1310.

- Aboul-Khair, S. A., Crooks, J., Turnbull, A. C., and Hytten, F. E., Clin. Sci., 1964, 27, 195.

10 Pochin, E. E., ibid., 1952, 11, 441.

1 Rivlin, R. S., Melmon, K. L., and Sjoerdsma, A., New Engl. F. Med., $1965,272,1143$.

${ }^{12}$ Melmon, K. L., Rivlin, R. S., Oates, J. A., and Sjoerdsma, A., F. clin. Endocr., 1964, 24, 691.
}

substance. Normal tyrosine tolerance after taking it was seen in nine pregnant women, four patients treated with oestrogens, and nine given exogenous iodine in contrast dyes for radiological examination.

The explanation of these findings is still obscure. Rivlin and his colleagues comment that the usefulness of the tyrosinetolerance test will ultimately depend on whether it is adequate to distinguish between thyrotoxic and euthyroid patients when the diagnosis cannot be made by other criteria. They suggest that it may have a role in the diagnosis of thyrotoxicosis when other tests of thyroid function are unreliable, as in pregnancy or after administration of iodide.

It is to be hoped that increased tyrosine tolerance may ultimately prove to be a specific feature of thyrotoxicosis. Nevertheless, as the authors' figures show, there were 18 patients in the group of 59 euthyroid and thyrotoxic patients whose results overlapped each other when the level of tyrosine in the plasma was measured 30 minutes after the tyrosine load. This fact suggests that much fuller experience is needed before the test can be accepted as clinically reliable.

\section{Medico-legal Mishaps}

The annual reports of two of the medical defence organizations $^{12}$ show that expenditure on damages and costs was higher than ever in 1964. But this increase is not wholly attributable to legal aid, a more informed public, and inflation. A few years ago it was exceptional for the Medical Defence Union to find that claims for negligence had any genuine foundations: this is no longer so. Many claims are now made which cannot be resisted.

Some medico-legal mishaps arise out of new hazards, as in the use of plastic catheters during intravenous therapy. ${ }^{3}$ But despite well-publicized memoranda from the defence organizations it is the old forms of carelessness and incompetence that give rise to the bulk of civil claims. Overlooked swabs and operations on the wrong limb or digit still give rise to claims. The Medical Defence Union again emphasizes that a surgeon does not discharge his responsibility if he relies exclusively on the theatre sister's swab and instrument counts, and that he must take all reasonable precautions to minimize his dependence on her counts-including a search of the operation field. Burns given under anaesthesia increase in number and in variety of causes. Hot-water bottles, electrical apparatus, hot instruments from the sterilizer, diathermy pads, and chemicals (particularly trichloracetic acid in treating bleeding from the nose) are among causes of burns referred to in the reports.

Many patients now want to understand what is going on, and this demands that a full explanation of the nature and effect of a proposed operation should be given before a consent form is presented for signature. For this reason amendments have been made to the forms of consent recommended by the defence organizations.

Representations supported by the defence organizations

1 Medical Defence Union, Annual Report, 1965.

2 Medical Protection Society, Annual Report, 1965.

3 Brit. med. F., 1963, 2, 1218

4 Addison, P. H., Constable, H., and Millar, C. C., ibid., 1965, 2, 596. 